\title{
Effectiveness of an Indoor Air Pollution (IAP) Intervention on Reducing IAP and Improving Women's Health Status in Rural Areas of Gansu Province, China
}

\author{
Yibin Cheng1* ${ }^{*}$, Jiaqi Kang1 ${ }^{*}$, Fan Liu1 ${ }^{1}$, Bryan A. Bassig' ${ }^{2}$, Brian Leaderer ${ }^{2}$, Gongli He1, \\ Theodore R. Holford'2, Ning Tang1, Jian Wang', Jian He', Yanchang Liu', Yingchun Liu', \\ Jiang Liu', Xun Chen'1, Heng Gu'1, Xiao Ma5, Tongzhang Zheng', Yinlong Jin' \\ ${ }^{1}$ Institute for Environmental Health and Related Product Safety, Chinese Center for Disease Control and \\ Prevention, Beijing, China \\ ${ }^{2}$ Yale School of Public Health, New Haven, USA \\ ${ }^{3}$ Chinese Center for Disease Control and Prevention, Beijing, China \\ ${ }^{4}$ Gansu Provincial Center for Disease Control and Prevention, Lanzhou, China \\ ${ }^{5}$ West China School of Public Health, Sichuan University, Chengdu, China \\ Email: ${ }^{*}$ inyinlong1951@sina.com, ${ }^{*}$ tongzhang.zheng@yale.edu
}

Received 16 February 2015; accepted 9 March 2015; published 13 March 2015

Copyright (C) 2015 by authors and Scientific Research Publishing Inc.

This work is licensed under the Creative Commons Attribution International License (CC BY).

http://creativecommons.org/licenses/by/4.0/

(c) ()

\section{Abstract}

Given the deleterious health effects associated with indoor air pollution (IAP), this study was conducted to evaluate an IAP intervention in rural areas in Gansu, one of the poorest provinces of China. We selected 371 rural households to take part in intervention measures including stove improvement and health education. Eight of 371 households were selected to conduct IAP sampling. Four hundred and thirteen women in these households completed a questionnaire and 49 women took part in lung function tests. After the intervention, $\mathrm{PM}_{4}$ levels reduced from $455 \mu \mathrm{g} / \mathrm{m}^{3}$ to $200 \mu \mathrm{g} / \mathrm{m}^{3}$ and $\mathrm{CO}$ reduced from $3.40 \mathrm{ppm}$ to $2.90 \mathrm{ppm}$ in indoor air. The percentage of predicted value of FEV1 and FVC improved to some degree after the intervention, but all the parameters of lung function assessment did not show a significant change. Prevalence rates of several symptoms associated with IAP significantly declined in the study population, compared with baseline levels. Intervention measures combining stove improvement with health education were effective in reducing IAP levels. Women's health status, including eye and respiratory symptoms, also showed improvement. However, the effect on lung function was not apparent and warranted additional follow-up. Similarly, evaluation of the long term effects of the IAP intervention will require future studies.

\footnotetext{
${ }^{*}$ Corresponding authors.
}

How to cite this paper: Cheng, Y.B., et al. (2015) Effectiveness of an Indoor Air Pollution (IAP) Intervention on Reducing IAP and Improving Women's Health Status in Rural Areas of Gansu Province, China. Open Journal of Air Pollution, 4, 26-37. 


\section{Keywords}

\section{Indoor Air Pollution, Biomass, Lung Function, Respiratory System}

\section{Introduction}

About $41 \%$ of the world's population use solid fuel (such as coal and biomass) for domestic cooking and heating, and a large proportion of this exposed population lives in less developed countries [1]. Globally, reliance on solid fuels has emerged as one of the ten most important threats to public health [2]. In 2010, household air pollution from solid fuels was among the top 3 risk factors contributing to the global burden of disease and was responsible for nearly 3.5 million deaths across the world [3]. These deaths occur predominantly in women and children, as women are normally responsible for food preparation and cooking, and infants and young children are usually with their mothers near the cooking area and therefore are more likely to be exposed. In addition to deaths, various health issues, such as respiratory diseases, lung function reduction, and eye infections, have been associated with IAP exposure as recently reviewed or reported by others [4]-[6]. For example, exposure to high levels of $\mathrm{SO}_{2}$ in the kitchen has been associated with a significantly higher prevalence of COPD among nonsmoking women [7]. Furthermore, women living in households that used biomass had a significantly higher prevalence of asthma than those in households using cleaner fuels, and the risk for asthma appeared to be higher for women than for men [8].

More than half of the Chinese population lives in rural areas where more than $80 \%$ of the households use solid fuels for cooking [9]. WHO estimates of the disease burden associated with this use in China had suggested that solid fuel use was responsible for about 342,450 COPD deaths and 17,720 lung cancer deaths for those aged $\geq 30$, and was also responsible for 3,204,900 total DALYs in China in 2002, which was equivalent to $1.6 \%$ of the national disease burden during that year [2]. A further $28 \%$ of global deaths caused by indoor smoke from solid fuels occur in China [10].

In 2002, the World Bank, in conjunction with the Institute of Environmental Health and Related Product Safety of the Chinese Center for Disease Control and Prevention (IEHS, China CDC), initiated an IAP intervention product called the Sustainable and Efficient Energy Use to Alleviate Indoor Air Pollution in Poor Rural Areas of China. The purpose of the project was to test the viability of both technological and behavioral interventions to mitigate IAP and improve human health, and the project was carried out in rural areas of 4 Chinese remote provinces including Gansu, Guizhou, Shaanxi, and Inner Mongolia. The IAP intervention involved stove improvement in each selected area and health education (behavior intervention) of the local residents with the goal of changing their traditional cooking methods, heating practices, and other lifestyles that might contribute to IAP [11] [12].

Some previous epidemiologic evidence has indicated the beneficial effects of stove improvement as far as associated reduced risks for lung cancer, pneumonia, and COPD in other rural areas in China following implementation, which suggests that such an intervention may be viable [13]-[15]. Here, we report the results assessing the effectiveness of the IAP intervention on reducing IAP and improving the health status in women in Hui County of Gansu Province. We report the effects of the intervention on multiple indices related to IAP mitigation, including changes in various symptoms of eye and respiratory diseases, measures of lung function, and assessment of $\mathrm{PM}_{4}$ and $\mathrm{CO}$ levels in a representative sample of the households both before and after the intervention period.

\section{Materials and Methods}

\subsection{Study Population}

Gansu, located in northwest China, is one of China's least developed provinces. The annual income per capita for rural residents in the province was estimated to be around US \$193 in 2002 according to the National Bureau of Statistics of China. Wood and crop residues are the main energy sources for domestic cooking and heating in this area. The regular heating season in the region is between November and April of the following year. Hui County was selected for the stove intervention study because households in this county commonly use tradition- 
al stoves with biomass for heating and cooking, which causes direct release of smoke into the indoor living environment. While some households had chimneys, the chimneys were installed too low (for example, lower than eave) and consequently the smoke can easily reenter into rooms and result in IAP. Moreover, very few families in the area installed ventilators in their kitchen.

A total of 413 women from 371 households were included in the stove intervention study. Households that met the following criteria were recruited for this study: 1) used biomass for heating and cooking before the intervention with traditional stoves, e.g. open fire, unvented stoves, or stoves without a smoke door; 2) included woman aged 18 and over and children under age 15;3) had residents who lived in Hui County continuously for more than one year at the time that the stove intervention began.

\subsection{Stove Improvement}

Stove types used in homes in this region before the intervention consisted of either open pits (Figure 1(a)) or hand stoves (Figure 1(b)), or traditional stoves with either no chimney in the home (Figure 1(c)) or a chimney that was installed too low to effectively mitigate IAP (Figure 1(d)). The improved stoves with a chimney that were used for the intervention (Figure 2(a) and Figure 2(b)) were specifically designed for the local residents and were pilot tested for effectiveness before the stove intervention, as described elsewhere [16]. The local technicians were trained and certified by the Chinese NIEHS and were responsible for the installation of the stoves and for training each of the residents on how to use the stoves. Because some of the traditional stoves were used by the subjects for heating, the improved stove was connected to a heating bed (called Kang as shown in Figure 2(c)) and thus could be used for heating purposes as well. Results from the pilot tests showed that emission of $\mathrm{PM}_{4}$ and CO reduced by $98 \%$ and $88 \%$, respectively, in controlled conditions [16]. Between August and November in 2004, all 371 participating families changed to a certified stove with a chimney for cooking and heating. The old stoves inside these homes were completely demolished and replaced by the improved stoves. All homes in this region use agricultural residue and wood as their primary source of fuel for cooking and heating, and these fuel types did not change over the course of this study.

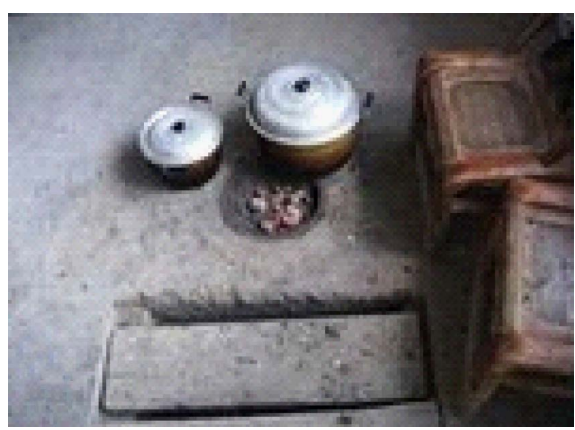

(a)

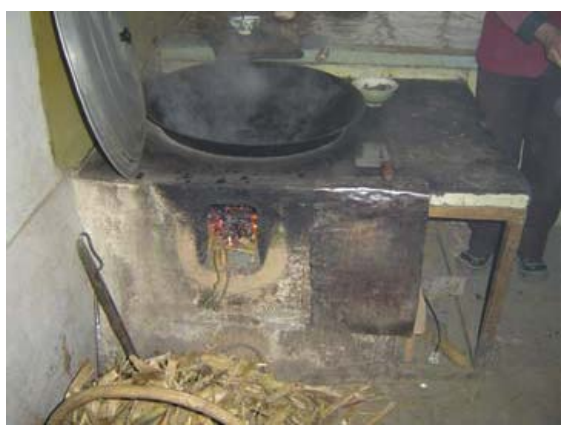

(c)

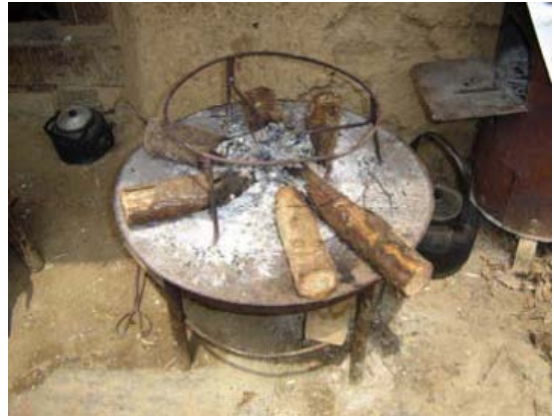

(b)

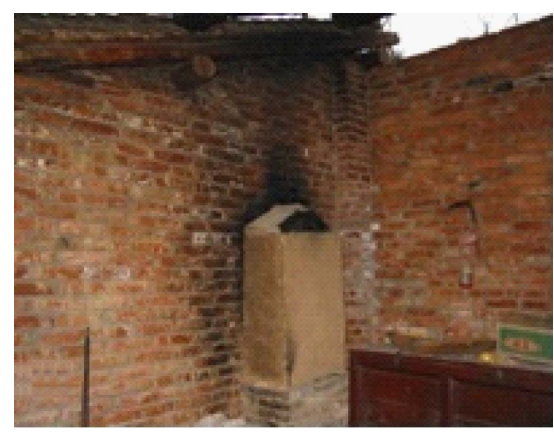

(d)

Figure 1. (a)-(d) Stoves used by the households in the study area before the intervention. Stoves used in this region before the intervention included either: open pits (a) or hand stoves (b), or traditional stoves with either no chimney in the home (c) or a chimney that was installed too low to effectively mitigate IAP (d). 


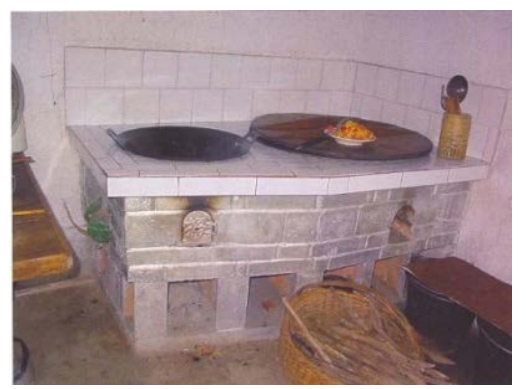

(a)

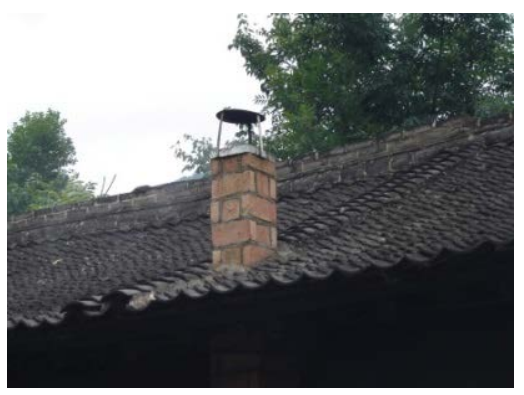

(b)

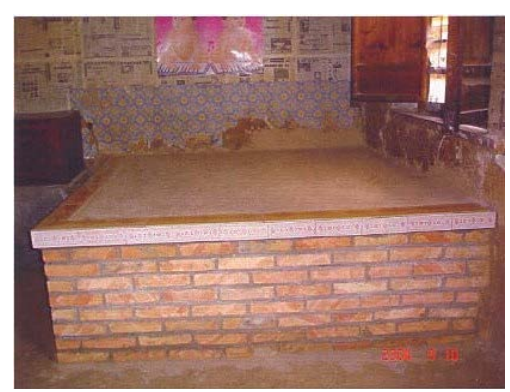

(c)

Figure 2. Improved stoves used by the households in the study area after the intervention. The improved stoves with a chimney that were used for the intervention (a) and (b) were specifically designed for the local residents. The improved stove was connected to a heating bed (called Kang as shown in (c).

\subsection{Health Education (Behavior Intervention)}

To encourage residents to actively participate in the stove improvement activities and correctly use the newly installed stoves, and to change lifestyle habits that may contribute to IAP or increasing exposure to IAP, scientists from IEHS, China CDC, and the Huaxi School of Public Health, Sichuan University, trained and worked with the local health professionals, village physicians, local stove technicians, and school teachers to educate the local residents during 2003 and 2005. This component included providing knowledge on the sources and impacts of IAP and information on correctly using and maintaining the stoves. Pamphlets describing methods to prevent IAP were distributed during household visits, health education classes, and other related activities. Three specific factors were evaluated to measure the impact of the behavior intervention, including use of a fan in the kitchen, opening of windows during the winter, and reduction in use of portable open fires to warm the pot tea.

\subsection{Assessment of Health and Intervention Effects}

Following informed consent, information on respiratory symptoms and occurrence of eye irritation/infections were collected through in-person interviews conducted by 30 trained interviewers. In both pre-intervention baseline interviews (during April, 2003) and post-intervention interviews (during April, 2005), participating women were asked to report their respiratory and eye symptoms during the 3 months before the interviews. The postintervention health assessments, including lung function testing, were conducted between 5 - 8 months after the improved stoves were installed during August-November 2004. Information on the type and amount of energy use, stove type, cooking habits, ventilation, heating, and other lifestyle and demographic data was also collected during the in-person interviews. A total of 49 women participated in both pre- and post-intervention lung function testing. These 49 women were similar to the overall study population with respect to demographic characteristics and cooking practices, as well as characteristics associated with the home, such as house area and presence of a short chimney. The pre-intervention spirometry was performed in April 2003 and post-intervention spirometry was conducted in April 2005 by technicians from IEHS, China CDC using a Multi-Functional Spirometer HI-801 (Chest M.I., INC, Tokyo, Japan). These technicians were trained before the field component of the study in accordance with the standardized steps of the ATS/ERS Task Force: Standardization of Lung Function Testing. The collected measurements on lung function parameters included vital capacity (VC), forced expiratory volume in 1 second (FEV1), forced vital capacity (FVC), and forced expiratory flow $25 \%-75 \%$ (FEF $25 \%-75 \%$ ). All lung function tests were conducted by trained personnel in the morning during the study period. For each of the lung function parameters, three measurements were taken and the best result of the 3 measurements was recorded and reported here.

\subsection{Assessment of Indoor Air Pollutants}

Because of the cost of monitoring and the willingness of the households, eight households were selected for IAP monitoring. These 8 families were selected to represent the geographic location, stove type, and type of biomass used in the region. $\mathrm{PM}_{4}$ and $\mathrm{CO}$ in the kitchen and bedroom were measured before (March 2003) and between 5-8 months after the stove intervention (March 2005). Indoor air samples were collected consecutively for 24 
hours in each of the 8 households. Respirable particles were measured according to the National Institute for Occupational Safety and Health of the United States (NIOSH, USA) protocol 0600, designed to capture particles with a median aerodynamic diameter of 4 ím (PM4). Samples were collected using a 10-mm nylon cyclone equipped with a 37-mm diameter poly vinyl chloride (PVC) filter (pore size 5ím supplied by SKC Inc., USA) at a flow rate of $2.5 \mathrm{l} / \mathrm{min}$. Air was drawn through the cyclone preselectors using battery-operated constant flow pumps (model PCXR8 supplied by SKC Inc., USA). All pumps were calibrated prior to and after each sampling day using a field minimeter, itself calibrated by a soap bubble meter in the laboratory. Pumps were also calibrated in the laboratory after each field exercise using the same minimeter. To maintain battery power throughout the sampling period, pumps were programmed to cover the 24-h interval through intermittent sampling (1 min out of every 4 - $6 \mathrm{~min}$ ). One field blank was taken on each sampling day.

Gravimetric analyses were conducted at the laboratory of the National Institute for Environmental Health and Related Products Safety, China CDC using an analytic microbalance (1/100,000, Sartorius 2004 MP, Germany) calibrated against standards provided by the Bureau of National Technological Control. All filters (field blanks and samples) were conditioned for 24 hours before weighing. The weighing facility temperature was set at 20 25 degrees $\mathrm{C}$ and humidity at $50 \% \pm 5 \%$. Respirable dust concentrations were calculated by dividing the blankcorrected increase in filter mass by the total air volume sampled [17]. Carbon monoxide (CO) was measured using long term diffusion tubes (manufactured by GASTEC, USA), with detection ranges of $10-200$ or $50-1000$ ppm [17].

\subsection{Statistical Analysis}

The 24 hour personal exposure to $\mathrm{PM}_{4}$ and $\mathrm{CO}$ in kitchen and bedroom air was compared for the pre- and postIAP intervention periods using the Wilcoxon signed rank test. Changes in lifestyles before and after the intervention were compared using McNemar's test. Lung function was assessed by calculating means and standard deviations based on observed values and the percentage of predicted values of each parameter. Predicted values were the average observed values in the population for any person of similar age, sex, and body composition, calculated in terms of predict equation for the Chinese population [18]. The percentages of predicted values were the ratios of observed values divided by the predicted value so that age, sex, and body composition would be adjusted by comparing the relative values. In addition to the possible change of body composition, we used linear mixed models to adjust for other factors including cooking years up to the date of survey, use of an open fire, not using fans in the kitchen, location of the kitchen in the home, and whether or not windows were opened when cooking. For the total study population (413 women), the effectiveness of the IAP intervention on reducing the respiratory and eye irritation symptoms was evaluated by logistic regression, adjusting for age, cooking years up to the date of the survey, using open fire, location of the kitchen, and never opening windows when cooking. For 49 spirometry participants, McNemar's test was used for the analysis of symptoms.

\section{Results}

\subsection{Characteristics of Study Population}

Characteristics of the study population based on data from the baseline survey are shown in Table 1. Over $80 \%$ of the subjects were between 18 - 39 years old and $99.8 \%$ of subjects were Han, the main ethnicity of China. Over $50 \%$ of the participants lived in households with 5 or more family members, and biomass was the main living fuel in all the selected households. $98.1 \%$ of women were responsible for cooking and $63.7 \%$ of subjects reported an average daily cooking time of 2 to 4 hours. None of the subjects were smokers, but $70 \%$ of them reported exposure to second-hand smoke. Very few women reported a change in their passive smoking exposure status after the intervention, compared to before because the interviews took place after such a short period following the stove improvement. The prevalence rates for all of the considered chronic diseases were low and were less than $5 \%$ in the study population.

\subsection{Changes of Stove Features and Behaviors}

The changes in stove features and behaviors relating to stove use associated with the intervention are shown in Table 2. Before the intervention, the percentages of stoves without chimneys, short chimneys (i.e., smoke exit lower than eaves), and stoves without smoke doors were $6.1 \%, 71.7 \%$ and $87.7 \%$, respectively. These traditional 
Table 1. Characteristics of the study population (\%).

\begin{tabular}{|c|c|c|}
\hline Variables & $\mathrm{n}$ & Percentage \% \\
\hline \multicolumn{3}{|l|}{ Age (baseline) } \\
\hline $18-29$ & 109 & 26.4 \\
\hline $30-39$ & 230 & 55.7 \\
\hline $40-49$ & 32 & 7.8 \\
\hline $50-59$ & 31 & 7.5 \\
\hline $60 \sim$ & 11 & 2.7 \\
\hline \multicolumn{3}{|l|}{ Ethnicity } \\
\hline Han & 412 & 99.8 \\
\hline Other & 1 & 0.2 \\
\hline \multicolumn{3}{|l|}{ Family members } \\
\hline 3 & 45 & 10.9 \\
\hline 4 & 135 & 32.7 \\
\hline 5 & 112 & 27.1 \\
\hline 6 & 84 & 20.3 \\
\hline$>6$ & 36 & 8.7 \\
\hline Missing & 1 & 0.2 \\
\hline Biomass use & 413 & 100.0 \\
\hline Cooking & 405 & 98.1 \\
\hline \multicolumn{3}{|c|}{ Everyday cooking time (hrs) } \\
\hline$<2$ & 105 & 25.4 \\
\hline $2 \sim$ & 263 & 63.7 \\
\hline $4 \sim$ & 39 & 9.4 \\
\hline $6 \sim$ & 6 & 1.5 \\
\hline Smoking & 0 & 0 \\
\hline Passive smoking & 289 & 70.0 \\
\hline \multicolumn{3}{|c|}{ History of diagnosed chronic diseases (\%) } \\
\hline Rhinitis & 3 & 0.7 \\
\hline Faucitis & 2 & 0.5 \\
\hline Tuberculosis & 2 & 0.5 \\
\hline Asthma & 1 & 0.2 \\
\hline Emphysema & 0 & 0 \\
\hline Chronic bronchitis & 9 & 2.2 \\
\hline Hypertension & 12 & 2.9 \\
\hline Heart disease & 14 & 4.1 \\
\hline Allergy & 4 & 1.0 \\
\hline
\end{tabular}

Table 2. Changes of stove features and behaviors before and after intervention (\%).

\begin{tabular}{|c|c|c|c|}
\hline Stove features and behaviors & Before $(n=413)$ & After $(n=413)$ & p-value ${ }^{b}$ \\
\hline Stoves without chimneys & 6.1 & 0 & - \\
\hline Short chimney (exit of chimney lower than eave) ${ }^{a}$ & 71.7 & 0 & - \\
\hline Stoves without smoke doors & 87.7 & 0 & - \\
\hline Portable open fire used for heating tea & 35.6 & 33.7 & 0.01 \\
\hline Fans installed in kitchen & 1.0 & 5.6 & $<0.01$ \\
\hline Never open window in winter & 16.0 & 11.1 & 0.048 \\
\hline
\end{tabular}

${ }^{\mathrm{a}}$ Twenty-five records were missing; ${ }^{\mathrm{b}} \mathrm{McNemar}$ 's Test. 
designs of the stoves were considered primary contributors to IAP in households that used biomass. Following the intervention, the percentages of stoves having each of these characteristics reduced to $0 \%$ (Table 2).

Alteration of behaviors associated with IAP exposure comparing the pre and post intervention periods are additionally shown in Table 2. These behaviors were compared to assess the health education component of the intervention. Using portable open fires to warm the pot tea, a tradition kept for hundreds of years in this region, decreased from $35.6 \%$ before the intervention to $33.7 \%$ after the intervention $(p=0.01)$. During the 2-year intervention, more households chose to buy and equip fans in kitchens to exhaust cooking smoke, and this use increased from $1.0 \%$ to $5.6 \%(\mathrm{p}<0.01)$ among enrolled participants. Furthermore, the percentage of participants who never opened windows during winter reduced from $16.0 \%$ to $11.1 \%$ over the course of the intervention pe$\operatorname{riod}(\mathrm{p}=0.048 ;$ Table 2).

\subsection{Improvement of Indoor Air Quality}

Households for IAP sampling were selected from the 371 households, considering house area, type of fuel used, stove features, and ventilation on the basis of a pilot study. Classifying by quantiles in accordance with questionnaire data of 413 women, the sample distribution of household areas was similar between the total population and the selected 8 households. Overall, the characteristics of the households were similar comparing the total study population and those households selected for sampling (Table 3), and in addition sociodemographic characteristics including income and education level were similar among women in households with and without IAP monitoring.

A comparison of $\mathrm{PM}_{4}$ and $\mathrm{CO}$ levels before and after the intervention stratified by room type is shown in Table 4 and Table 5. The average concentration of $\mathrm{PM}_{4}$ decreased by about $70 \%$, from 774 to $223 \mu \mathrm{g} / \mathrm{m}^{3}$, in the kitchen following implementation of the intervention, though this effect was marginally significant $(p=0.08)$ due to the small sample size. Conversely, there was no observed decrease in the average bedroom concentrations of $\mathrm{PM}_{4}$ following the intervention (pre $135 \mu \mathrm{g} / \mathrm{m}^{3}$ vs. post $176 \mu \mathrm{g} / \mathrm{m}^{3} ; \mathrm{p}=0.20$ ), whereas the average $\mathrm{PM}_{4}$ levels of the bedroom and kitchen combined were decreased by about $56 \%$ following the intervention (pre $455 \mu \mathrm{g} / \mathrm{m}^{3}$ vs. post $200 \mu \mathrm{g} / \mathrm{m}^{3} ; \mathrm{p}=0.46$ ). The concentration of $\mathrm{PM}_{4}$ in the bedrooms was lower than that in the kitchen both before and after stove improvement (Table 4).

The average concentrations of $\mathrm{CO}$ in both the kitchen and bedroom were reduced following the intervention (Table 5). Specifically, CO levels decreased in the kitchen from $3.81 \mathrm{ppm}$ to $3.00 \mathrm{ppm}$, while concentrations reduced from $2.99 \mathrm{ppm}$ to $2.80 \mathrm{ppm}$ in the bedroom. For both rooms combined, CO levels changed slightly, declining from $3.40 \mathrm{ppm}$ to $2.90 \mathrm{ppm}$, although none of these reductions of $\mathrm{CO}$ were statistically significant (Table 5).

\subsection{Changes of Health Indicators of Women}

Changes in lung function following the intervention are reported in Table 6. Spirometry of women showed that FEV1 increased from $2.33 \pm 0.54 \mathrm{~L} / \mathrm{s}$ to $2.46 \pm 0.44 \mathrm{~L} / \mathrm{s}$ and FVC increased from $2.75 \pm 0.70 \mathrm{~L}$ to $2.84 \pm 0.56 \mathrm{~L}$ comparing the levels before and after the intervention. The percentage of predicted value of FEV1 (pre-intervention $86.7 \% \pm 18.8 \%$ vs. post-intervention $93.9 \% \pm 14.5 \%$ ) and FVC (pre-intervention $89.9 \% \pm 21.8 \%$ vs. post-intervention $95.0 \% \pm 16.3 \%$ ) improved to some degree after the intervention, but all the parameters of lung function assessment did not show significant change. In the 49 participants who had lung function assessed, the prevalence of self-reported eye and respiratory symptoms that occurred in the past 3 months from the post- intervention survey decreased for all symptoms examined compared to the reported prevalence from baseline, including tearing, sore eyes, red eyes, runny nose, nose congestion, continuous sneeze, phlegm, and fever (Table 7).

Among the total study population, a similar reduction in the percent prevalence of all examined symptoms was apparent following the intervention compared to baseline (Table 7). Significant reductions were observed for the prevalence of tearing, which decreased from $5.6 \%$ to $0 \%$, sore eyes which decreased from $3.6 \%$ to $1.5 \%$, and for red eyes which decreased from $3.9 \%$ to $1.0 \%$. Further, there were significant reductions in the percentage of participants reporting phlegm (pre $6.8 \%$ vs. post $3.4 \% ; \mathrm{p}=0.01$ ) and fever (pre $5.3 \%$ vs. post $1.7 \%$; $\mathrm{p}<$ 0.01 ; Table 7).

\section{Discussion}

The results from this intervention suggest that stove improvement and associated behavioral changes related to 
Table 3. Selected characteristics of households for questionnaire survey and for IAP monitoring (\%).

\begin{tabular}{ccc}
\hline & $\begin{array}{c}\text { Households for questionnaire survey } \\
(\mathbf{n}=\mathbf{4 1 3})\end{array}$ & $\begin{array}{c}\text { Households for IAP monitoring } \\
(\mathbf{n}=\mathbf{8})\end{array}$ \\
\hline House area $\left(\mathrm{m}^{2}\right)^{\mathrm{a}}$ & 14.6 & 12.5 \\
$<60$ & 33.0 & 25.0 \\
$60-79$ & 22.3 & 25.0 \\
$80-99$ & 30.1 & 37.5 \\
$100 \sim$ & 100.0 & 100.0 \\
Biomass use & 88.1 & 75.0 \\
Stoves without smoke door & & 87.5 \\
\hline
\end{tabular}

${ }^{\mathrm{a}}$ Household areas were classified by quantiles based on the data of questionnaire survey. One record was missed; ${ }^{\mathrm{b}} \mathrm{Two}$ records were missing; ${ }^{\mathrm{c}} \mathrm{Thir}-$ ty-three records were missing.

Table 4. Comparison of $\mathrm{PM}_{4}$ levels before and after intervention $\left(\mu \mathrm{g} / \mathrm{m}^{3}\right)$.

\begin{tabular}{|c|c|c|c|c|c|c|}
\hline Sampling spots & Time & $\mathrm{N}^{\mathrm{a}}$ & Mean & $\mathrm{SD}$ & Median & p-value ${ }^{b}$ \\
\hline \multirow{2}{*}{ Kitchen } & Before & 8 & 774 & 756 & 568 & \multirow{2}{*}{0.08} \\
\hline & After & 8 & 223 & 104 & 197 & \\
\hline \multirow{2}{*}{ Bedroom } & Before & 8 & 135 & 149 & 100 & \multirow{2}{*}{0.20} \\
\hline & After & 8 & 176 & 28 & 163 & \\
\hline \multirow{2}{*}{ Total } & Before & 8 & 455 & 621 & 183 & \multirow{2}{*}{0.46} \\
\hline & After & 8 & 200 & 77 & 163 & \\
\hline
\end{tabular}

${ }^{\mathrm{a}}$ Sample size of households for IAP monitoring; ${ }^{\mathrm{b}}$ Wilcoxon signed rank test comparing data before and after intervention.

Table 5. Comparison of $\mathrm{CO}$ levels before and after intervention (ppm).

\begin{tabular}{|c|c|c|c|c|c|c|}
\hline Sampling spots & Time & $\mathrm{N}^{\mathrm{a}}$ & Mean & SD & Median & $\mathrm{p}$-value ${ }^{\mathrm{b}}$ \\
\hline \multirow{2}{*}{ Kitchen } & Before & 8 & 3.81 & 3.25 & 5.26 & \multirow{2}{*}{0.94} \\
\hline & After & 8 & 3.00 & 1.57 & 3.05 & \\
\hline \multirow{2}{*}{ Bedroom } & Before & 8 & 2.99 & 2.79 & 2.31 & \multirow{2}{*}{0.84} \\
\hline & After & 8 & 2.80 & 1.77 & 2.53 & \\
\hline \multirow{2}{*}{ Total } & Before & 8 & 3.40 & 2.96 & 3.81 & \multirow{2}{*}{0.72} \\
\hline & After & 8 & 2.90 & 1.62 & 2.86 & \\
\hline
\end{tabular}

${ }^{\mathrm{a}}$ Sample size of households for IAP monitoring; ${ }^{\mathrm{b}}$ Wilcoxon signed rank test comparing data before and after intervention.

Table 6. Changes in lung function before and after intervention $(n=49)$.

\begin{tabular}{ccccccccc}
\hline \multirow{2}{*}{ Variables } & \multicolumn{2}{c}{ Observed } & \multicolumn{2}{c}{ Percentage predicted (\%) } & $\begin{array}{c}\text { Mean } \\
\text { changes }^{\mathbf{a}}\end{array}$ & $\mathbf{t}^{\mathbf{b}}$ & p-value $^{\mathbf{b}}$ \\
\cline { 2 - 7 } & Before & After & Before & After & & \\
VC (L) & $3.20 \pm 0.57$ & $3.10 \pm 0.51$ & $104.5 \pm 18.3$ & $103.6 \pm 16.0$ & -0.9 & 0.32 & 0.75 \\
FVC (L) & $2.75 \pm 0.70$ & $2.84 \pm 0.56$ & $89.9 \pm 21.8$ & $95.0 \pm 16.3$ & 5.1 & 1.11 & 0.27 \\
FEV1 (L/s) & $2.33 \pm 0.54$ & $2.46 \pm 0.44$ & $86.7 \pm 18.8$ & $93.9 \pm 14.5$ & 7.1 & 1.91 & 0.06 \\
FEF 25\% - 75\% & $2.87 \pm 0.85$ & $2.71 \pm 0.56$ & $87.9 \pm 26.9$ & $84.5 \pm 17.2$ & -3.5 & -1.61 & 0.12 \\
(L/s) & & &
\end{tabular}

${ }^{\mathrm{a}}$ Mean changes based on percentage predicted value of lung function (the values after intervention were subtracted by the values before intervention); ${ }^{\mathrm{b}}$ Adjusted using a linear mixed model for cooking years up to date of survey, using open fire, no fans in kitchens, location of kitchen and never opening windows when cooking. 
Table 7. Prevalence rates of symptoms before and after intervention among spirometry participants and total subjects (\%).

\begin{tabular}{|c|c|c|c|c|c|c|}
\hline \multirow{2}{*}{ Symptoms } & \multicolumn{2}{|c|}{ Spirometry participants } & \multirow{2}{*}{$\begin{array}{l}(n=49) \\
\text { p-value }^{a}\end{array}$} & \multicolumn{2}{|c|}{ Total subjects } & \multirow{2}{*}{$\begin{array}{r}(n=413) \\
p^{p-v a l u e}\end{array}$} \\
\hline & Before & After & & Before & After & \\
\hline Tearing & 14.3 & 2.0 & 0.01 & 5.6 & 0 & - \\
\hline Sore eyes & 8.2 & 4.1 & 0.41 & 3.6 & 1.5 & 0.04 \\
\hline Red eyes & 12.2 & 2.0 & 0.06 & 3.9 & 1.0 & 0.01 \\
\hline Runny nose & 2.0 & 0 & - & 2.2 & 1.5 & 0.70 \\
\hline Nose congestion & 4.1 & 0 & - & 2.7 & 1.0 & 0.11 \\
\hline Continuous sneeze & 6.1 & 0 & - & 2.4 & 1.2 & 0.34 \\
\hline Phlegm & 8.2 & 4.1 & 0.41 & 6.8 & 3.4 & 0.01 \\
\hline Fever & 10.2 & 2.0 & 0.10 & 5.3 & 1.7 & $<0.01$ \\
\hline
\end{tabular}

${ }^{a} \mathrm{McNemar}$ 's Test; ${ }^{\mathrm{b}}$ Adjusted for age, cooking years up to date of survey, using open fire, location of kitchen and never open windows when cooking using logistic regression.

fuel use, such as opening windows while cooking, may be effective in mitigating the negative health consequences associated with IAP. Specifically, we observed a reduction in average $\mathrm{PM}_{4}$ levels, particularly in the kitchen area, and in the prevalence of symptoms associated with IAP following implementation of the stove improvement and behavioral intervention. Further, FEV1 favorably increased following the intervention compared to baseline, although this effect was not statistically significant. The households selected for IAP assessment were shown to be representative of the larger study population with respect to home area, fuel type used, and stove features and ventilation practices, suggesting that our findings may be generalizable to the overall study population. While the average bedroom concentration of $\mathrm{PM}_{4}$ was slightly higher after stove improvement, this is potentially attributed to the small sample size of monitored households and/or the limited duration of each measurement period (i.e., 24 hours).

Since few nations have indoor air quality standards for $\mathrm{PM}_{4}$, we can only compare the result with the limit for $\mathrm{PM}_{10}$ in domestic air. In China, the national standard for indoor air quality dictates that the average concentration of $\mathrm{PM}_{10}$ should not exceed $150 \mu \mathrm{g} / \mathrm{m}^{3}$ [19]. While stove improvement was demonstrated to reduce $\mathrm{PM}_{4}$ levels, the concentration of $\mathrm{PM}_{4}$ in indoor air was still higher than this standard for $\mathrm{PM}_{10}$. Using solid fuels was the root of IAP in rural households for the limit of economic status. It would be difficult to reduce the indoor air pollutants to very low levels unless clean fuels were prevalent in rural households. While our results indicated significant behavioral modifications concerning fuel use habits, some lifestyles, such as using portable open fires to heat tea, were still popular after the intervention. Consequently, this may have contributed to the relatively high levels of $\mathrm{PM}_{4}$ even after stove improvement in some households.

Changes in $\mathrm{CO}$ levels generally suggested a mild trend of decline, but the measured concentrations were lower than expected. Specifically, 24 hour average concentrations of $\mathrm{CO}$ before and after intervention were consistently below current standards and guidelines (i.e., WHO guideline values of $5.6 \mathrm{ppm} / 7 \mathrm{mg} / \mathrm{m}^{3}$ for $24 \mathrm{~h}$ exposures), and in some cases CO concentrations were close to the detection limits of the diffusion tubes. Since these were 24-h concentrations, concentrations may have been higher during cooking or when doors and windows were closed at night, but this was not observable in our data [16]. Furthermore, about $83 \%$ of the surveyed women use to open windows in the winter and $84 \%$ opened kitchen windows for ventilation when cooking even before the behavior intervention; therefore, generated $\mathrm{CO}$ may have diffused to others rooms or outdoors. For both $\mathrm{CO}$ and $\mathrm{PM}_{4}$, the percent reduction in levels before and after the intervention in the field study were lower compared to previously conducted controlled tests [16]. This may primarily be due to other factors associated with levels of these pollutants, such as individual cooking practices and ventilation patterns, and also due to the fact that the controlled tests were conducted only during periods when the stove was burning.

In our study, socioeconomic differences, individual biological variations, and some potential confounders that might affect lung function among populations were controlled because we compared the changes in the same people before and after intervention. In addition, we transformed the observed values to percentages of predicted values in order to control for age and possible changes of body composition during the 2 -year study period, and 
used linear mixed models to assess the improvement of lung function parameters, adjusting for other potential confounders. In some follow-up studies on lung function, spirometry results may have been affected by participants who repeated the test several times and developed experience and skills to perform better on the respiratory function test [20]. However, this was unlikely to have influenced the results in our study given the relatively long interval between the first and second lung function assessments. Data in this study suggested the possible improvement of FEV1 in women to some degree after IAP mitigation. However, this finding should be interpreted cautiously since other parameters of lung function did not show similar improvement. The post-intervention examination of lung function was conducted roughly 5 months after the large-scale stove intervention. It would be unlikely for these parameters to improve right after intervention measures had been taken. Follow-up studies are warranted in order to evaluate the long term effect of IAP mitigation on lung function.

On the other hand, we observed significant decreases in the prevalence rates of some eye and respiratory symptoms, as well as for fever, following the intervention. In other community studies carried out in developing countries, investigators also found that biomass exposure was consistently associated with chronic respiratory symptoms although effects on lung function were variable or small [5] [20] [21]. These studies suggested that symptoms were more sensitive to variation of IAP levels. Since accurate disease records were not available in this region, the symptoms survey was alternatively used to measure the variation in health status. Given that eye and respiratory symptoms reflect stimulation of the mucosas and aggravation or attack of diseases, the decreases in prevalence of these symptoms provide a potential indication of improvement in health status following the intervention and reduction in IAP levels. Our results also indicated similarly decreasing trends in the prevalence of symptoms in the 49 women who took part in the lung function test, which suggested health improvement after intervention similar to the overall study population. These women also had relatively higher prevalence rates of all symptoms except runny nose during the baseline period and more significant reduction in the post-intervention interview. This might be attributed to the fact that people in poorer health condition were more likely to participate in the IAP mitigation activities and would get more improvement in health. However, we note that the study personnel and participants in the study were not blinded to the intervention status, and therefore there is a possibility of biased reporting for the subjective physical symptoms. In addition, it is possible that some reported symptoms may have been due to other causes aside from the effects of IAP, although participants were asked about the prevalence of symptoms over a three month period before the interview, which provided some determination of whether the symptoms were chronic in nature rather than from acute respiratory infections.

There were some additional limitations in this study. First, combustion of solid fuels was the source of indoor air pollutants in rural regions of China. However, it would not be feasible to implement cleaner energy (e.g. natural gas and electricity) given the poor economic conditions among the rural households and undeveloped infrastructure. The primary goal of this intervention was therefore to inform the public of the adverse effects of IAP from biomass and assist them in replacing traditional stoves. The appearance, usage, and maintenance of the new stoves were similar to the traditional ones and thus the effect of the intervention is likely to be sustainable. Second, the exposure assessment conducted in our study utilized area sampling for a relatively short time period (i.e., 24 hours) rather than using personal monitors for the study subjects. This approach provided a general indication of the levels of IAP in the monitored households, but might not capture the variability in exposures and could either underestimate or overestimate personal exposure depending on the placement of the monitors in relation to the participants' usual activities. Third, our study was relatively small in terms of the number of monitored households and subjects included in lung function testing, and the timeline of the project required a shorter than ideal interval between the baseline and follow-up periods and therefore follow-up studies will be needed. Finally, some risk behaviors practiced for generations were difficult to change in the one- or two-year intervention period.

\section{Conclusion}

In conclusion, we have shown that an intervention consisting of stove improvement and behavioral modifications related to fuel use may be an effective and viable method to mitigate the deleterious health effects of IAP in developing regions. Specifically, our results suggest that such an intervention may reduce levels of $\mathrm{PM}_{4}$ and physical symptoms associated with IAP exposure, and in addition may improve some measures of lung function, although the effects reported in our study are not statistically significant due to the relatively small size of our study and the symptoms assessed are based on self-report. Follow-up studies with a longer assessment period 
between the pre and post intervention periods are clearly needed to properly evaluate changes in lung function associated with these stove improvements, as well as the long-term effects of the intervention.

\section{Acknowledgements}

The authors would like to express special gratitude to all the study subjects in the study and the personnel in the area of Gansu Province, China, which have supported the study. Funding for this work was provided by the World Bank through financial support from the Energy Sector Management Assistance Program (ESMAP), Department for International Development, UK (DFID) and Swedish International Development Agency (SIDA) and also partly supported by Fogarty training grants D43TW 008323 and D43TW 007864-01 from the National Institutes of Health.

\section{References}

[1] World Health Organization (2013) World Health Statistics. http://www.who.int/gho/publications/world health_statistics/2013/en/

[2] World Health Organization (2007) Indoor Air Pollution: National Burden of Disease Estimates. World Health Organization, Geneva. http://www.who.int/indoorair/publications/indoor_air_national burden_estimate revised.pdf

[3] Lim, S., Vos, T., Flaxman, A.D., Danaei, G., Shibuya, K., Adair-Rohani, H., et al. (2012) A Comparative Risk Assessment of Burden of Disease and Injury Attributable to 67 Risk Factors and Risk Factor Clusters in 21 Regions, 1990-2010: A Systematic Analysis for the Global Burden of Disease Study 2010. The Lancet, 380, 2224-2260. http://dx.doi.org/10.1016/S0140-6736(12)61766-8

[4] Kurmi, O.P., Semple, S., Simkhada, P., Smith, W.C. and Ayres, J.G. (2010) COPD and Chronic Bronchitis Risk of Indoor Air Pollution from Solid Fuel: A Systematic Review and Meta-Analysis. Thorax, 65, 221-228. http://dx.doi.org/10.1136/thx.2009.124644

[5] Regalado, J., Perez-Padilla, R., Sansores, R., Paramo Ramirez, J.I., Brauer, M., Pare, P., et al. (2006) The Effect of Biomass Burning on Respiratory Symptoms and Lung Function in Rural Mexican Women. American Journal of Respiratory and Critical Care Medicine, 174, 901-905. http://dx.doi.org/10.1164/rccm.200503-479OC

[6] Díaz, E., Smith-Sivertsen, T., Pope, D., Lie, R.T., Díaz, A., McCracken, J., et al. (2007) Eye Discomfort, Headache and Back Pain among Mayan Guatemalan Women Taking Part in a Randomised Stove Intervention Trial. Journal of Epidemiology and Community Health, 61, 74-79. http://dx.doi.org/10.1136/jech.2006.043133

[7] Liu, S., Zhou, Y., Wang, X., Wang, D., Lu, J., Zheng, J., et al. (2007) Biomass Fuels Are the Probable Risk Factor for Chronic Obstructive Pulmonary Disease in Rural South China. Thorax, 62, 889-897. http://dx.doi.org/10.1136/thx.2006.061457

[8] Mishra, V. (2003) Effect of Indoor Air Pollution from Biomass Combustion on Prevalence of Asthma in the Elderly. Environmental Health Perspectives, 111, 71-78. http://dx.doi.org/10.1289/ehp.5559

[9] Mestl, H.E., Aunan, K., Seip, H.M., Wang, S., Zhao, Y. and Zhang, D. (2007) Urban and Rural Exposure to Indoor Air Pollution from Domestic Biomass and Coal Burning across China. Science of the Total Environment, 377, 12-26. http://dx.doi.org/10.1016/j.scitotenv.2007.01.087f

[10] World Health Organization (2009) Global Health Risks: Mortality and Burden of Disease Attributable to Selected Major Risks. http://www.who.int/healthinfo/global_burden_disease/GlobalHealthRisks_report_full.pdf

[11] Jin, Y., Ma, X., Chen, X., Cheng, Y., Baris, E. and Ezzati, M. (2006) Exposure to Indoor Air Pollution from Household Energy Use in Rural China: The Interactions of Technology, Behavior, and Knowledge in Health Risk Management. Social Science Medicine, 62, 3161-3176. http://dx.doi.org/10.1016/j.socscimed.2005.11.029

[12] He, G., Ying, B., Liu, J., Gao, S., Shen, S., Balakrishnan, K., et al. (2005) Patterns of Household Concentrations of Multiple Indoor Air Pollutants in China. Environmental Science Technology, 39, 991-998. http://dx.doi.org/10.1021/es049731f

[13] Chapman, R.S., He, X., Blair, A.E. and Lan, Q. (2005) Improvement in Household Stoves and Risk of Chronic Obstructive Pulmonary Disease in Xuanwei, China: Retrospective Cohort Study. British Medical Journal, 331, 1050. http://dx.doi.org/10.1136/bmj.38628.676088.55

[14] Lan, Q., Chapman, R.S., Schreinemachers, D.M., Tian, L. and He, X. (2002) Household Stove Improvement and Risk of Lung Cancer in Xuanwei, China. Journal of the National Cancer Institute, 94, 826-835. http://dx.doi.org/10.1093/jnci/94.11.826

[15] Shen, M., Chapman, R.S., Vermeulen, R., Tian, L., Zheng, T., Chen, B.E., et al. (2009) Coal Use, Stove Improvement, and Adult Pneumonia Mortality in Xuanwei, China: A Retrospective Cohort Study. Environmental Health Perspectives, 
117, 261-266. http://dx.doi.org/10.1289/ehp.11521

[16] Zhou, Z., Jin, Y., Liu, F., Cheng, Y., Liu, J., Kang, J., et al. (2006) Community Effectiveness of Stove and Health Education Interventions for Reducing Exposure to Indoor Air Pollution from Solid Fuels in Four Chinese Provinces. Environmental Research Letters, 1, 1-12. http://dx.doi.org/10.1088/1748-9326/1/1/014010

[17] Jin, Y., Zhou, Z., He, G., Wei, H., Liu, J., Liu, F., et al. (2005) Geographical, Spatial, and Temporal Distributions of Multiple Indoor Air Pollutants in Four Chinese Provinces. Environmental Science Technology, 39, 9431-9439. http://dx.doi.org/10.1021/es0507517

[18] Mu, K. and Liu, S. (1990) National Compilation of Normal Value of Lung Function. Peking Union Medical College, Beijing Medical University Joint Publishing House, Beijing.

[19] Ministry of Health (2002) Indoor Air Quality Standard Ministry of Health, China. http://www.moh.gov.cn/publicfiles//business/htmlfiles/zwgkzt/pwsbz/index.htm

[20] Smith-Sivertsen, T., Diaz, E., Pope, D., Lie, R.T., Diaz, A., McCracken, J., et al. (2009) Effect of Reducing Indoor Air Pollution on Women's Respiratory Symptoms and Lung Function: The RESPIRE Randomized Trial, Guatemala. American Journal of Epidemiology, 170, 211-220. http://dx.doi.org/10.1093/aje/kwp100

[21] Rinne, S., Rodas, E., Bender, B., Rinne, M., Simpson, J., Galer-Unti, R., et al. (2005) Relationship of Pulmonary Function among Women and Children to Indoor Air Pollution from Biomass Use in Rural Ecuador. Respiratory Medicine, 100, 1208-1215. http://dx.doi.org/10.1016/j.rmed.2005.10.020 